\title{
Reformas electorales en Ecuador: los pendientes hacia la igualdad y no discriminación en un Estado plurinacional e intercultural
}

\section{Electoral reforms in Ecuador: the pending towards equality and non-discrimination in a plurinational and intercultural State}

Dayana Litz León Franco

Recepción: 26 de septiembre de 2018

Aceptación: 11 de octubre de 2018

\begin{abstract}
Resumen
En el contexto de la discusión de las reformas electorales es sustancial que exista en el país una construcción colectiva con las implicaciones activas y las propuestas de todos los pueblos y nacionalidades, considerando que la Constitución de la República señala que "las comunidades, pueblos, y nacionalidades indígenas, el pueblo afroecuatoriano, el pueblo montubio y las comunas forman parte del Estado ecuatoriano, único e indivisible". En este sentido, el artículo aborda el contexto y los retos para contar con unas reformas electorales apegadas a las garantías de los derechos por la igualdad y no discriminación.

Palabras clave: democracia comunitaria, reformas electorales, inclusión, Estado Plurinacional e Intercultural.

\section{Abstract}

In the context of the discussion of electoral reforms, it is essential that there be a collective construction in the country with the active implications and proposals of all peoples and nationalities, considering that the Constitution of the Republic states that "communities, peoples, and indigenous nationalities, the Afro-Ecuadorian people, the "Montubio" people and the communes are part of the Ecuadorian State, unique and indivisible ". In this context, the article addresses the context and the challenges to have electoral reforms attached to the guarantees of rights for equality and nondiscrimination.

Key words: community democracy, electoral reforms, social inclusion, Plurinational and Intercultural State.
\end{abstract}




\section{Introducción}

n Ecuador existe la prohibición de "realizar reformas legales en materia electoral durante el año anterior a la celebración de elecciones" (Constitución de la República, 2008: art.117); en este contexto la norma suprema, en el mismo artículo, también señala:

"En caso de que la declaratoria de inconstitucionalidad de una disposición afecte el normal desarrollo del proceso electoral, el Consejo Nacional Electoral propondrá a la Función Legislativa un proyecto de ley para que ésta lo considere en un plazo no mayor de treinta días; de no tratarlo, entrará en vigencia por el ministerio de la ley" (Constitución de la República, 2008: art.117).

En ese sentido, existe un importante punto de partida para analizar en el contexto ecuatoriano las reformas electorales pendientes, tras el análisis de los procesos electorales que se han llevado a cabo luego de la aprobación mediante referéndum popular de la Constitución de la República, en el año 2008, y la aprobación de la Ley Orgánica Electoral y de Organizaciones Políticas, Código de la Democracia, en el 2009.

En esta trayectoria importante de la aplicación de la normativa se ha avanzado en la aplicación e identificación de los nudos críticos en torno a la participación y organización del poder, considerando los principios constitucionales desde la organización colectiva, donde se establece como mandato que "la participación de la ciudadanía en todos los asuntos de interés público es un derecho, que se ejercerá a través de los mecanismos de la democracia representativa, directa y comunitaria" (Constitución de la República, 2008: art.95). Si bien, en Ecuador, se han desarrollado procesos enfocados a la democracia representativa y directa, aún está pendiente en el país una reforma electoral donde se incluya en el Código de la Democracia, porque no están definidos ni precisados, los conceptos, los alcances y la aplicación de un mecanismo de la democracia como es la comunitaria.

Considerando los elementos anteriores, el presente análisis profundizará en aspectos esenciales de las reformas electorales desde una mirada por la igualdad y no discriminación, específicamente el vinculado con 
el Estado plurinacional e intercultural, que debe partir del reconocimiento al Estado ecuatoriano como social de derechos y justicia, "intercultural, plurinacional y laico"; y que entre sus deberes primordiales está "fortalecer la unidad nacional en la diversidad"2; y precisa que "las comunidades, pueblos, y nacionalidades indígenas, el pueblo afroecuatoriano, el pueblo montubio y las comunas forman parte del Estado ecuatoriano, único e indivisible"3.

Tanto los procesos de consolidación de un Estado Plurinacional e Intercultural, -que es la base histórica y democrática del Ecuador-, como la consolidación de una participación con igualdad y no discriminación, parten de la construcción colectiva de las acciones y determinaciones de los seres humanos, así como de sus expresiones diferentes, divergentes, disidentes y contestatarias, con procesos de vida particulares y una autodefinición diversa.

\section{La democracia ecuatoriana: un balance histórico de las demandas históricas}

De acuerdo con una trayectoria en torno a conceptos y análisis sobre democracia, y de forma específica la comunitaria, este apartado parte de una conceptualización abordada por De la Torre (2009): "la democracia comunitaria se basa en los principios de reciprocidad, en la deliberación de todos en las decisiones, en la obligación de asumir cargos de poder y responsabilidad y en la rotación de los cargos. En estas formas de democracia los derechos individuales son parte de los fines colectivos y no se diferencian las esferas legislativa, ejecutiva y judicial". Mientras que, Ortiz (2012: 5), señala lo siguiente: "la democracia comunitaria hace relación a la

\footnotetext{
1.De acuerdo con la Constitución de la República (2008), en su artículo 1: "El Ecuador es un Estado constitucional de derechos y justicia, social, democrático, soberano, independiente, unitario, intercultural, plurinacional y laico. Se organiza en forma de república y se gobierna de manera descentralizada. La soberanía radica en el pueblo, cuya voluntad es el fundamento de la autoridad, y se ejerce a través de los órganos del poder público y de las formas de participación directa previstas en la Constitución. Los recursos naturales no renovables del territorio del Estado pertenecen a su patrimonio inalienable, irrenunciable e imprescriptible".

2.Conforme al numeral 3 del artículo 3 de la Constitución de la República del Ecuador (2008): "Son deberes primordiales del Estado (...) 3. Fortalecer la unidad nacional en la diversidad".

3. Hace referencia al artículo 56 de la Constitución de la República del Ecuador (2008) está dentro del Capítulo Cuarto sobre "Derechos de las comunidades, pueblos y nacionalidades".
} 
organización política de sociedades poco diferenciadas; y se fundamenta en la participación permanente de todos los miembros de una colectividad, en la cual prima el bien común sobre el individual (cfr. Villoro, 2006)”.

Si se profundiza en lo que posteriormente Villoro (2011) manifestara, se tiene un análisis que no se desliga de la existencia de diferentes tipos de democracia. El autor hace una división en dos particularmente: una, la "liberal"; y, la otra, la denominada por autores como la "republicana" o "comunitaria". Sobre esta última, precisa:

"En Rousseau podemos encontrar fundamentos de esa doctrina, que se desarrolla sólo en las primeras etapas de las revoluciones democráticas, la norteamericana (en su corriente antifederalista) y la francesa (en el partido jacobino). La democracia republicana presenta rasgos comunes con la democracia comunitaria. Las primeras ideas republicanas trataban de mantener o recuperar la vida de comunidades pequeñas de carácter agrario. Recordemos la defensa, tanto de Thomas Jefferson como de John Adams, de una organización agraria de la economía opuesta a la industralización, por ser garante, en su opinión, de preservar la pureza y la simplicidad propias de las virtudes republicanas o comunitarias" (Villoro, 2011).

Se toma como referencia, en este caso, que en Bolivia "además de la democracia liberal existe la democracia comunitaria que está presente en los alluys aymaras y quechuas, y que se manifestó en las ciudades con fuerte presencia indígena durante las rebeliones del 2000 y del 2003" (De la Torre, 2009).

El ejemplo boliviano posee una referencia de hace más de una década de García (2004) donde señala la coexistencia en el país de una desarticulación en "varias civilizaciones pero donde la estructura estatal sólo recoge la lógica organizativa de una sola de estas civilizaciones: la moderna mercantil capitalista"; y añade que "un régimen civilizatorio es un conjunto coherente de estructuras generativas de orden material, político y simbólico que organizan de manera diferenciada las funciones productivas, los procesos técnicos, los sistemas de autoridad, la organización política, además de los esquemas 
simbólicos con los que colectividades extensas dan coherencia al mundo".

Por tanto, precisa el autor entre los grandes regímenes civilizatorios de Bolivia a la civilización comunal, donde se incluyen "procedimientos tecnológicos fundados en la fuerza de masa, en la gestión de la tierra familiar y comunal, en la fusión entre actividad económica y política, con sus propias autoridades e instituciones políticas que privilegian la acción normativa sobre la electiva y en la que la individualidad es un producto de la colectividad y su historia pasada".

La importancia de detallar el caso de Bolivia en un artículo sobre el contexto ecuatoriano, es porque a los dos países les unen raíces e historia desde América del Sur; así como sus constituciones hacen mención a la democracia comunitaria.

En el Capítulo Tercero de la norma suprema boliviana, donde se refiere al sistema de Gobierno, precisa en su artículo 11 que "La República de Bolivia adopta para su gobierno la forma democrática participativa, representativa y comunitaria, con equivalencia de condiciones entre hombres y mujeres". Mientras que la democracia se ejerce de formas como la comunitaria "por medio de la elección, designación o nominación de autoridades y representantes por normas y procedimientos propios de las naciones y pueblos indígenas originarios campesinos, entre otros, conforme a Ley".

Por su parte, Tapia (2010) indicó que los principios de complementariedad y reciprocidad son fundamentales en las culturas andinas; e indicó:

"La construcción de un estado plurinacional implica que no sólo se trata de reformar a las relaciones entre estado y sociedad civil o entre ciudadanos y gobierno y estructuras estatales, que pertenecen en última instancia a un mismo tipo de sociedad, sino que lo que se trata de articular de nuevo modo estructuras sociales provenientes de diferentes matrices de sociedad, además de poblaciones que se han socializado o formado en diferentes conjuntos de relaciones sociales, cosmovisiones, lenguas y también bajo diferentes estructuras de autoridad. En este sentido, es claro que primero hay que recordar cómo es que se han constituido 
estas fuerzas que han generado la coyuntura constituyente, en particular los sujetos que se constituían con cierto grado de exterioridad y de interioridad en las condiciones de configuración de lo que había de estado y de estado-nación en Bolivia" (Tapia, 2010).

Estos aspectos coexisten con una realidad internacional, pues de acuerdo con cifras del Banco Mundial (2008), en el contexto mundial habitan "alrededor de 370 millones de indígenas en más de 90 países. Si bien constituyen el 5 $\%$ de la población mundial, los pueblos indígenas representan alrededor del $15 \%$ de las personas que viven en pobreza extrema. Aunque los pueblos indígenas son propietarios, ocupan o utilizan un cuarto de la superficie terrestre, ellos protegen el $80 \%$ de la biodiversidad que aún queda en el planeta". Por tanto, sus aportes en el desarrollo territorial y la sostenibilidad de las naciones es sustancial; por tanto, cuando hablamos de lo comunitario no hay que desconectar estos elementos intersectoriales.

\section{Reformas electorales en Ecuador pendientes por la igualdad y no discriminación}

En Ecuador, de acuerdo con la Agenda Nacional para la Igualdad de Nacionalidades y Pueblos (ANINP) 2013 - 2017, existen las cifras reflejadas en el siguiente gráfico, donde se hace referencia al último Censo de Población y Vivienda realizado en el Ecuador en el año 2010, así como un comparativo con el del 2001. 


\section{Gráfico 1.}

Autoidentificación de la población (ANINP, 2013-2017)

CENSO 2001-2010

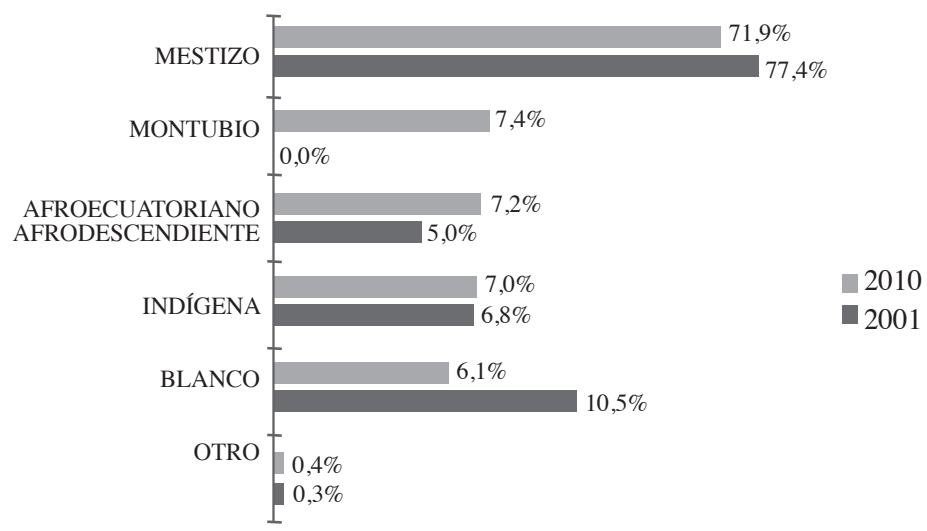

Fuente: CODENPE, 2012.

Como se visualiza en el anterior gráfico, en Ecuador la población montubia es del 7,4\%, la afroecuatoriana el 7,2\% y la indígena es del 7,0\%; siendo un Estado con una autoidentificación mestiza como mayoritaria en un $71,9 \%$, cifra que disminuyó con relación al Censo del 2001 que era del 77,4\%.

Esta realidad que no sólo desafía a las políticas económicas, sociales, culturales y territoriales en el país, sino a la aplicación de una democracia comunitaria, donde son protagonistas las comunidades, las comunas, los pueblos y las nacionalidades. Con respecto a este mecanismo establecido en el artículo 95 de la Constitución de la República (2008), se precisa que sigue en permanente construcción e "inicia con el reconocimiento de lo que somos ${ }^{4}$ y es "una construcción colectiva desde lo diverso" 4,5 .

En el caso de las reformas electorales en el ámbito de la democracia comunitaria, existen dos aspectos que deberían constituir elementos

4. Consejo Nacional Electoral de la República del Ecuador e Instituto de la Democracia (2015). Cartilla 5. Democracia comunitaria e interculturalidad. Programa ABC de la Democracia. CNE / IDD - Ecuador.

5. Ibídem. 
esenciales dentro de la Ley Orgánica Electoral y de Organizaciones Políticas, Código de la Democracia: el primero, es la transversalización del enfoque intercultural en todas las fases de los procesos electorales y de las determinaciones en el contexto de la democracia interna de las organizaciones políticas, enfatizando en la democracia representativa y directa; y, el segundo, es la claridad con respecto a la autonomía, siguiendo los aportes de Grijalva (2012: 74), que "debe entenderse en el sentido que lo establece la Constitución, esto es, como la competencia para designar sus propias autoridades, generar sus propias normas y decisiones y ejercitar facultades jurisdiccionales. En otras palabras, los sistemas jurídicos de cada nacionalidad son expresión directa de su autonomía".

Al contar con una mirada integral de los tres mecanismos de participación en democracia, profundizaremos en el Estado plurinacional de forma más efectiva; y no potenciando un solo tipo de democracia, que aunque se constituye en sí misma desde el origen de todas las formas de decisión por el bien común, debe también estar fortalecida por una sociedad que canalice su participación y demandas con enfoque intercultural.

Hay una precisión clave en el tema relacionado con la autonomía indígena como un ámbito de expresión de la democracia intercultural, tal y como lo señala Mayorga (2017); quien especifica que "las autonomías indígenas son el espacio político para la vigencia de la democracia comunitaria. Su materialización institucional es parsimoniosa y sigue dos rutas: referendo para la conversión de un municipio en autonomía indígena y trámite administrativo para el reconocimiento de territorios indígenas en autonomías territoriales con instancias de gobierno". Por tanto, en el caso ecuatoriano, las reformas en este sentido no solo deben estar enfocadas a lo establecido en el Código de la Democracia, sino en el Código Orgánico de Organización Territorial, Autonomía y Descentralización (COOTAD).

\section{Conclusiones}

Para que el proceso de reformas electorales sea efectivo en el ámbito de la democracia comunitaria no se debe dejar a un lado lo que señaló Agustín 
Grijalva en su publicación Del presente se inventa el futuro: justicias indígenas y Estado en Ecuador:

"En efecto, la plurinacionalidad sin interculturalidad se reduciría a un agregado de nacionalidades sin proyecto común ni relaciones, mientras que la interculturalidad sin plurinacionalidad quedaría reducida a un ideal de relaciones intersubjetivas igualitarias sin transformación política e institucional que esta nueva igualdad requiere. Las justicias indígenas precisamente son evidencias vivas de que plurinacionalidad e interculturalidad no son dimensiones opuestas sino complementarias" (Grijalva, 2012: 74).

Para finalizar, las reformas hacia la igualdad y no discriminación en el Código de la Democracia, ha considerado en el presente artículo el camino de casi una década sin la aplicación efectiva, partiendo de las demandas de los pueblos y nacionalidades, de quienes poseen la herencia del conocimiento y la historia, indicando que desde las realidades de las comunidades y las comunas, es donde se identifican las potencialidades de cada uno de sus ejercicios democráticos.

Han existido importantes esfuerzos en el país, por conocer las demandas como el Proyecto "ABC de la Democracia" -impulsado desde el CNE e Instituto de la Democracia-, sin embargo, es necesario que el Ecuador asista a una construcción colectiva de las reformas electorales donde la Función Legislativa y la Función Electoral ejerzan un trabajo de coordinación en la administración pública desde los diferentes territorios, y donde estén presentes las voces de todos los pueblos y nacionalidades. La democracia comunitaria no puede ser definida en la normativa dentro de un recinto legislativo ni desde una institucionalidad.

También existen otros aspectos pendientes para que el sistema electoral sea más igualitario, e ir aportando a un Estado con igualdad y no discriminación, en la medida en que las personas ejerzan roles en democracia, ya sea desde un ámbito de acción colectiva, de participación partidaria como de ciudadanía empoderada; o de seres humanos pasivos e inactivos que decidan vincularse e involucrarse en las decisiones políticas de su país. 
En el caso de la acción colectiva, Garretón (2002) señala: “Los cambios estructurales y culturales que afectan tanto al tipo societal latinoamericano como al modo clásico de relación entre Estado y sociedad significan, en términos de la acción colectiva, un cambio de paradigma en un doble sentido". Mientras que en las conclusiones de su análisis en La transformación de la acción colectiva en América Latina, manifiesta sobre la "la matriz constituyente de actores sociales (relación entre Estado, representación, régimen y base socioeconómica y cultural), al desarticularse una determinada relación entre Estado y sociedad que llamamos nacional-popular y que privilegiaba la dimensión política en la constitución de actores sociales, asistimos al desaparecimiento de un principio eje o estructurador del conjunto de estos actores"; mientras que la matriz configurativa, que hace referencia a la "combinación de niveles y dimensiones y de esferas y ámbitos en que se ubica la acción o el actor"; el autor indica que "pasaríamos tentativa y ambiguamente de actores básicamente económico-políticos y centrados en el nivel históricoestructural de las sociedades a actores definidos socioculturalmente y por referencia a los mundos de la vida (subjetividad) y a las instrumentalidades organizacionales e institucionales".

Los aspectos e interrelaciones entonces, entre las expresiones de la democracia comunitaria, como de la acción colectiva de diversos actores en una sociedad de necesarios consensos, tiene que contar con una armonía entre las diferentes matrices que expresa Garretón (2002): la matriz constituyente y la matriz configurativa; sin que una predomine sobre otra, sino que coexistan en una democracia que requiere de los disensos y la autocrítica, para ser más democrática.

Esto se conjuga con un concepto muy necesario como integridad electoral y que lo analiza Nohlen (2016); sobre este tema manifiesta que "en su reciente expansión que empieza a sustituir en América Latina al de la justicia electoral en su sentido amplio", y en su conceptualización contempla dos dimensiones: la primera tiene un alcance integrador donde se "asume una visión integral de todas las dimensiones del ciclo electoral partiendo del diseño de la legislación y de los organismos y la selección de autoridades electorales, hasta los procesos de votación, conteo, divulgación de resultados 
y fiscalización.” (Centro de Estudios Políticos, 2014 cit. en Nohlen, 2016). La segunda, está relacionada con lo siguiente:

"La calidad de las elecciones, precisamente a la relación entre valores y prácticas. Postula la correspondencia entre valores y normas por un lado y comportamientos y resultados por el otro: el sinónimo de tal aspiración es la honestidad. Integridad electoral se determina como el postulado ético, dirigido al proceso electoral en total, a los individuos involucrados en él, para comportarse de forma íntegra, o sea honesta, conforme a los valores y las normas que sustentan elecciones democráticas, y para proteger, en su caso, la honestidad del proceso electoral frente a desafíos que la ponen en cuestión" (Nohlen, 2016).

Este es un desafío latente para cada protagonista de los sistemas democráticos partiendo de sus roles, incluida la institucionalidad en Ecuador donde, de acuerdo con el artículo 217 de la Constitución de la República del Ecuador (2008), la Función Electoral garantiza "el ejercicio de los derechos políticos que se expresan a través del sufragio, así como los referentes a la organización política de la ciudadanía (...) estará conformada por el Consejo Nacional Electoral y el Tribunal Contencioso Electoral. Ambos órganos tendrán sede en Quito, jurisdicción nacional, autonomías administrativa, financiera y organizativa, y personalidad jurídica propia. Se regirán por principios de autonomía, independencia, publicidad, transparencia, equidad, interculturalidad, paridad de género, celeridad y probidad". (Constitución de la República del Ecuador, 2008).

Otros temas en este contexto, hacia la igualdad e inclusión, también siguen pendientes: uno, lo ha asumido la institucionalidad mediante el Pleno del Consejo Nacional Electoral - Transitorio (CNE-T), que determinó "la creación de una comisión especializada para el análisis de las propuestas en materia de reformas a la Ley Orgánica Electoral y de Organizaciones Políticas - Código de la Democracia; así como llevar adelante diferentes actividades para promover el debate en esta materia" ${ }^{\text {" }}$. En este contexto, fueron recibidos

6. Fuente: Boletín de Prensa del Consejo Nacional Electoral de la República del Ecuador: “Asambleístas conocieron la relación entre los métodos de asignación de escaños y el principio de proporcionalidad”. Disponible en la URL: http:/cne.gob.ec/es/institucion/sala-de-prensa/noticias/4586-asambleistas-conocieron-la-relacion-entre-los-metodos-de-asignacion-de-escanos-y-el-principio-de-proporcionalidad, visitada el 08 de octubre de 2018 . 
las y los Consejeros en Comisión General en el pleno de la Asamblea Nacional el 04 de octubre de 2018, donde se desarrolló la conferencia "El Principio Constitucional de Proporcionalidad", por parte del ingeniero Rafael Estrella Aguilar, "autor del libro Webster vs D'Hondt, expuso a los legisladores sobre cómo los diferentes métodos de asignación de escaños contribuyen o distorsionan el cumplimento del principio de proporcionalidad establecido en la Constitución, en el artículo 116"?.

En otro ámbito, también existen aspectos que faltan para consolidar como un sistema electoral igualitario con las reformas al Código de la Democracia que estén vinculados con la inclusión de la violencia política ${ }^{8}$ contra las mujeres y las personas LGBTI, definición establecida dentro de la Ley Orgánica Integral para Prevenir y Erradicar la Violencia contra las Mujeres, ${ }^{9}$ que fue publicada en el Registro Oficial en febrero de 2018; así como el establecimiento de mecanismos claros de prevención, atención y sanción a todos los actos que explícita e implícitamente estén en contra del derecho de participación democrática por parte de las mujeres y personas LGBTI. Las inequidades en el acceso vs. representación de las mujeres, es también un reto pendiente que debe ser analizado en procesos de democracia interna de las organizaciones políticas. ${ }^{10}$

Esto da la medida que las reformas electorales no deben precisarse de manera separada y desarticulada hacia la igualdad y no discriminación, es por ello que sus análisis deben contar con una mirada integral a los enfoques que emanen del artículo 11 de la Constitución de la República (2008), donde explícitamente se

\section{Ibídem.}

8.La Ley Orgánica Integral para Prevenir y Erradicar la Violencia contra las Mujeres define en su artículo 10 a la violencia política como uno de los tipos de violencia y señala que "aquella violencia cometida por una persona o grupo de personas, directa o indirectamente, en contra de las mujeres que sean candidatas, militantes, electas, designadas o que ejerzan cargos públicos, defensoras de derechos humanos, feministas, lideresas políticas o sociales, o en contra de su familia. Esta violencia se orienta a acortar, suspender, impedir o restringir su accionar o el ejercicio de su cargo, o para inducirla u obligarla a que efectúe en contra de su voluntad una acción o incurra en una omisión, en el cumplimiento de sus funciones, incluida la falta de acceso a bienes públicos u otros recursos para el adecuado cumplimiento de sus funciones".

9.La Ley Orgánica Integral para Prevenir y Erradicar la Violencia contra las Mujeres fue publicada en el Registro Oficial de la República del Ecuador Nro. 175 del Lunes, 5 de febrero de 2018.

10. León (2018) precisa que "en el contexto ecuatoriano, y tomando como referencia las Elecciones Seccionales a realizarse en el año 2019 existen, a partir del análisis con enfoque y perspectiva de género lo siguiente: primero, fortalecer los mecanismos de participación política de las mujeres para que exista una mayor representación en los diferentes ámbitos de gobiernos autónomos descentralizados; y, segundo, garantizar un acceso con igualdad de oportunidades, donde se evidencie y se comuniquen en todos los niveles, 
manifiesta que "todas las personas son iguales y gozarán de los mismos derechos, deberes y oportunidades. Nadie podrá ser discriminado por razones de etnia, lugar de nacimiento, edad, sexo, identidad de género, identidad cultural, estado civil, idioma, religión, ideología, filiación política, pasado judicial, condición socioeconómica, condición migratoria, orientación sexual, estado de salud, portar VIH, discapacidad, diferencia física; ni por cualquier otra distinción, personal o colectiva, temporal o permanente, que tenga por objeto o resultado menoscabar o anular el reconocimiento, goce o ejercicio de los derechos". Por tanto, estos serían enfoques fundamentales para consolidar una democracia más inclusiva.

Lo más relevante de este proceso es comprender que ser actores en democracia tiene una profunda conexión con sus historias y expresiones ancestrales, en la medida que la democracia vuelva al lugar donde nace, desde lo común y lo compartido, que emerge en el seno de la comunidad.

\section{Referencias}

Agenda Nacional para la Igualdad de Nacionalidades y Pueblos (ANINP) 2013 2017 de la República del Ecuador.

Banco Mundial (2018). Pueblos Indigenas. Disponible en la URL: https://www. bancomundial.org/es/topic/indigenouspeoples, visitada el 07 de septiembre de 2018.

Consejo Nacional Electoral (2018). Nota de prensa: “Asambleístas conocieron la relación entre los métodos de asignación de escaños y el principio de proporcionalidad". Disponible en la URL: http://cne.gob.ec/es/institucion/ sala-de-prensa/noticias/4586-asambleistas-conocieron-la-relacion-entrelos-metodos-de-asignacion-de-escanos-y-el-principio-de-proporcionalidad, visitada el 08 de octubre de 2018.

Constitución de la República del Ecuador (2008).

Constitución Política del Estado Plurinacional de Bolivia.

De la Torre, C. (2009). "Populismo radical y democracia en los Andes". Journal 
of Democracy en español, 1(1), 24-37.

Garretón, M. A. (2002). La transformación de la acción colectiva en América Latina. Revista de la CEPAL.

García, A. (2004). Democracia liberal vs. democracia comunitaria. Interculturalidad, descolonización del estado y del conocimiento. 71-86.

Grijalva, Agustín. (2002) "Del presente se inventa el futuro: justicias indígenas y Estado en Ecuador", En Santos, Boaventura de Sousa y Grijalva, Agustín. "Justicia indigena, plurinacionalidad e interculturalidad en Ecuador". Quito: Fundación Rosa Luxemburg-Edcs.Abya Yala, Págs.51-76.

Pachano, S. (2011). Calidad de la democracia e instituciones políticas en Bolivia, Ecuador y Perú. Flacso-Sede Ecuador.

León, Dayana (2018). "Mujeres en democracia: retos en el ejercicio de sus derechos políticos y de participación ciudadana con perspectiva de género". Caso ecuatoriano. Revista Democracia \& Elecciones. Disponible en la URL https://bit.ly/2ISJp0u, visitada el 25 de julio de 2018.

Nohlen, D. (2016). “Arquitectura institucional, contexto sociocultural e integridad electoral”. Desafios, 28(1), 399-426.

Ortiz, R. (2012) Cuaderno de Estudio Electoral No. 1. "Sistema político y sistema electoral en Ecuador". Instituto de la Democracia; Quito, Ecuador.

Tapia, L. (2010). Consideraciones sobre el Estado plurinacional. Descolonización en Bolivia: Cuatro ejes para comprender el cambio.

Villoro, Luis (2006). Democracia comunitaria, conferencia dictada en el InstitutoTecnológico Autónomo de México, el 21 de noviembre de 2006, México.

Villoro, Luis (2011). "Democracia". Revista Desinformémonos, enero 2011. Disponible en la URL: http://desinformemonos.org/2011/01/d-e-m-o-c-r-ac-i-a/print/ 